\title{
Первая находка метана в оливине из незатронутых серпентинизацией ультрамафитов
}

\author{
Чащухин И.С., Вотяков С.Л., Панкрушина Е.А.
}

Институт геологии и геохимии им. акад. А.Н. Заварицкого Уральского отделения РАН, Екатеринбург

Аннотация. В оливинах уральских несерпентинизированных ультрамафитов трех формационных типов - урало-аляскинского, орогенного и офиолитового - обнаружены цепочки тонких включений размером от 2 до $20 \mu \mathrm{m}$. Изучение газового состава методом рамановской спектроскопии в широком диапазоне значений рамановского сдвига 800-4300 см-1 показало, что все включения представлены метаном. Исключительно метановый состав включений, независимо от формационной принадлежности ультрамафитов, позволяет сделать вывод об их генерации в близких условиях, на границе переходная зона - верхняя мантия.

Ключевые слова: ультрамафит, метан, серпентинизация, рамановская спектроскопия, летучесть кислорода.

\section{First methane finding in the olivine from ultramafites unaffected by serpentinization}

\author{
Chashchukhin I.S., Votyakov S.L., Pankrushina E.A. \\ Institute of Geology and Geochemistry, Ural Branch of the Russian Academy of Sciences
}

\begin{abstract}
In olivines of the Ural non-serpentinized, ultramafic rocks of three formation types - Ural-Alaskan, orogenic and ophiolitic - chains of thin inclusions from 2 to $20 \mu \mathrm{m}$ in size were found. The study of the gas composition by Raman spectroscopy in a wide range of Raman shift values of 800-4300 $\mathrm{cm}^{-1}$ showed that all inclusions are represented by methane. The exclusively methane composition of inclusions, regardless of the formation of ultramafic rocks, allows us to conclude that they are generated under close conditions, at the transition zone - upper mantle boundary.In English.
\end{abstract}

Key words: ultramafite, methane, serpentinization, Raman spectroscopy, oxygen volatility.

\section{введение}

Флюидный режим в системе С-О-Н играет существенную роль на различных этапах формировании ультрамафитов, начиная с частичного плавления пиролита мантии и заканчивая поверхностным выветриванием. Наибольшую сложность представляет определение состава флюидов в глубинных частях Земли. Поэтому очень важны прямые свидетельства «дыхания недр». Изучение ультрамафитов Урала позволяет пополнить наши знания по данной проблеме.

К настоящему времени в ультрамафитах Урала известны два эпизода выброса газов, на 80-90 \% представленного водородом: при бурении скважины в дунитах Нижнетагильского массива и при проходке шахты «Молодежная» на хромитовом месторождении «40 лет Казахской ССР» в Кемпирсайском массиве (Лидин и др., 1982). Существенно водородный состав газа в массивах двух главных формационных типах ультрамафитов Урала - Урало-Аляскинском и офиолитовом позволило авторам предположить «общность причин, обусловивших газоносность глубоких горизонтов этих массивов», но сама «природа газоносности недостаточно ясна». В работе (Уханов и др., 1987) было показано, что изотопный состав водорода в шахте «Молодежная» имеет чрезвычайно легкий состав - $\delta \mathrm{D}=-744-766$ \% SMOW; авторами был обсужден ряд альтернативных гипотез о природе водорода, наиболее вероятными им представлялись следующие: водород имеет глубинное происхождение, при этом его легкий изотопный состав обусловлен низкотемпературным обменом с водой; водород образуется при окислении $\mathrm{Fe}^{2+} \rightarrow \mathrm{Fe}^{3+}$ при гидратации (серпентинизации) ультрамафитов. Результаты последующих низкотемпературных экспериментов по изотопному обмену водорода между серпентинизированным дунитом и дистиллированной водой (Девирц и др., 1992) исключили связь образования водорода с глубинным источником.

В работе (Melcher et al., 1997) было показано, что состав ГЖВ в рудной хромшпинели Кемпирсайского массива значимо варьирует от преимущественно водного (до 95 мол. \%) до существен- 


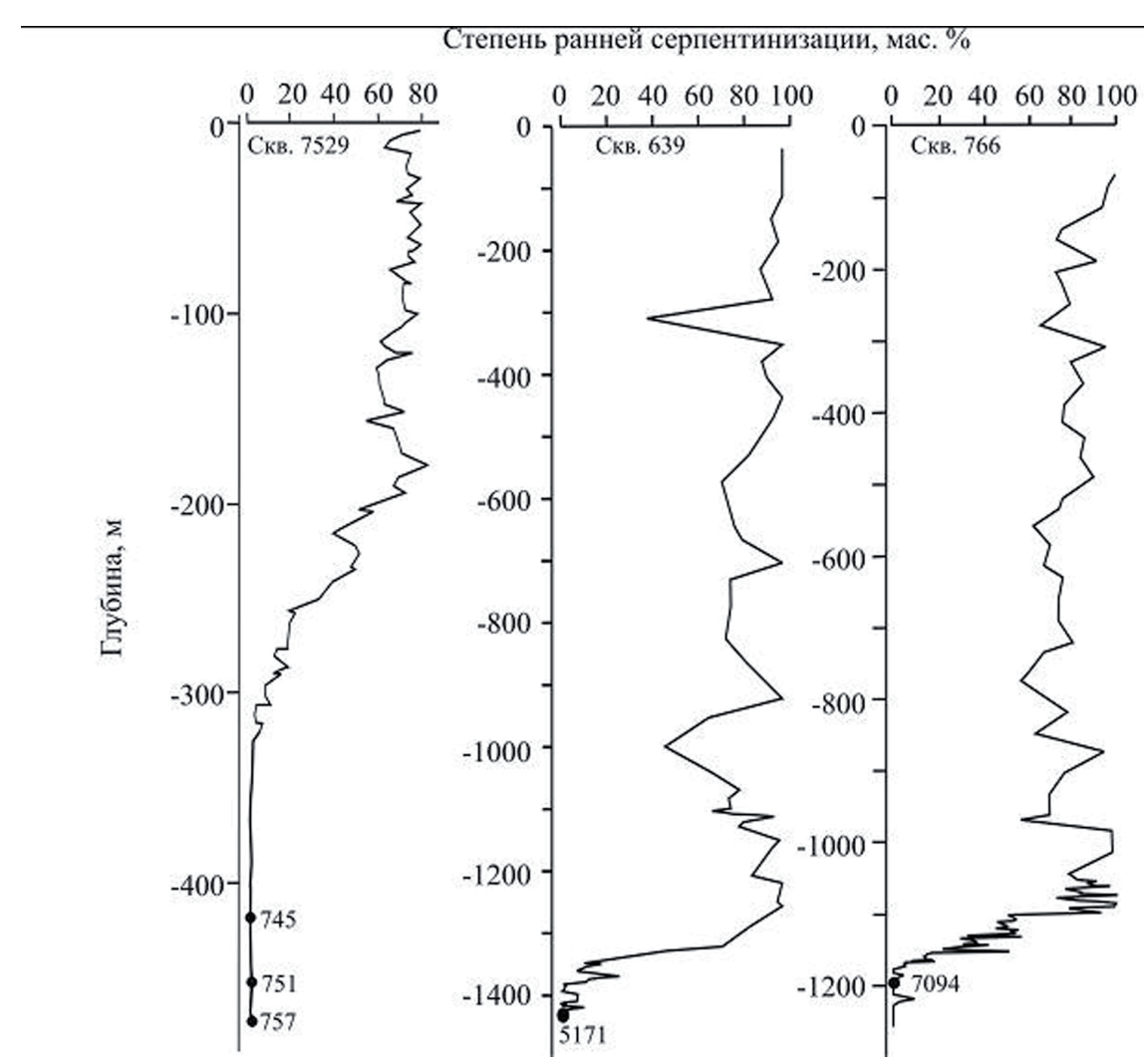

Рис. 1. Вариации степени ранней серпентинизации ультрамафитов, определенной по величине потерь при прокаливании (плотности ультрамафитов), в кернах скважин 7529, 639 и 766 и места отбора исследованных образцов.

Fig. 1. The variations of the early serpentinization degree of ultramafic rocks determined by loss on ignition (ultramafic density), in the cores of wells 7529, 639 and 766 and the place of sampling of the studied samples.

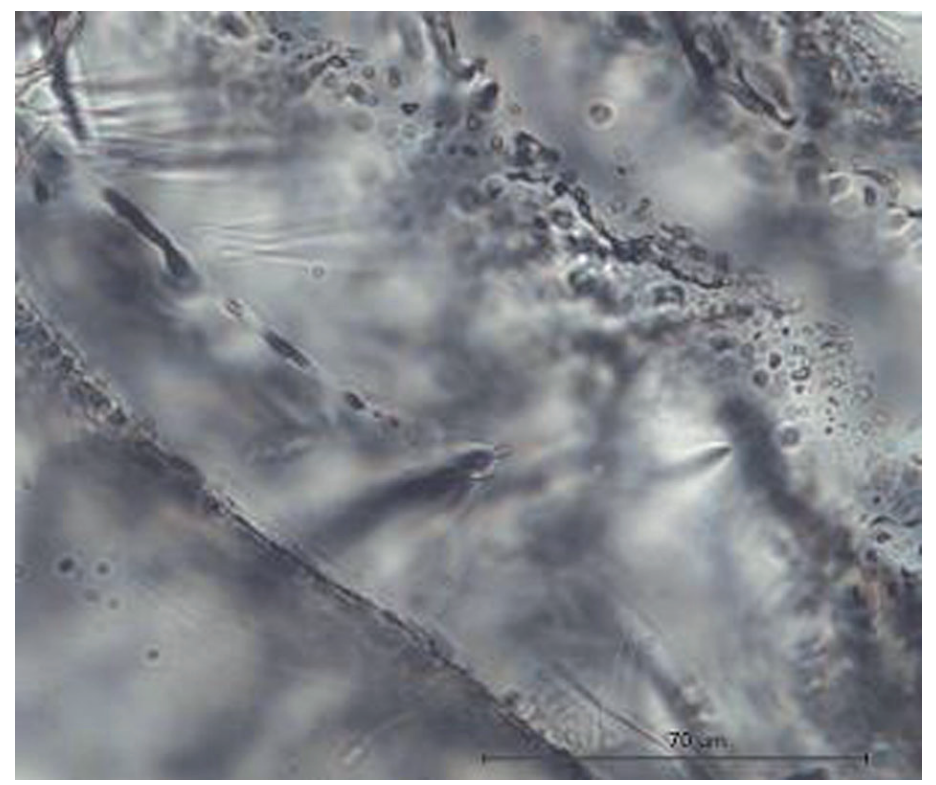

Рис. 2. Газовые включения в зерне оливина из несерпентинизированного дунита Нижнетагильского массива (скв. 7529, глубина 415 м). Оптический микроскоп Olimpus BX-51.

Fig. 2. Fluid inclusion in olivine sample from non-serpentine dunite of the Nizhnetagilsky massif (well 7529, depth 415 m). Olimpus BX-51 optical microscope. но водородного (до 69 \%) при содержании метана от 0.1 до 5.7 \%. Это позволяет предположить, что существовало, по крайней мере, два источника флюидов, связанных с рудообразованием и серпентинизацией. Приведенные данные характеризуют ультрамафиты, испытавшие раннюю петельчатую серпентинизацию. В настоящей работе для исключения ее влияния изучен состав ГЖВ в пробах оливина из керна трех глубоких скважин, отобранных ниже проникновения серпентинизации и вдали от тел хромититов (рис. 1).

Важно отметить, что эти скважины $(7529,639,766)$ пройдены в ультрамафитах трех формационных типов: первая пробурена по дунитам Нижнетагильского массива (Платиноносный пояс Урала) и практически повторила профиль ранее описанной скважины (Лидин и др., 1982); вторая вскрыла дунит- 
гарцбургит-лерцолитовую серию юго-восточного блока и третья - гарцбургиты западного блока Кемпирсайского массива. По составу пород, редокс-состоянию, степени хромитоносности ультрамафитов и составу рудной хромшпинели есть основания отнести дунит-гарцбургит-лерцолитовую серию к орогенным ультрамафитам, а вторую - к офиолитам (Чащухин и др., 2007). Различий в химическом составе свежих и рассчитанном на сухой остаток серпентинизированных ультрамафитов не обнаружено. Исследованы оливины из 9 образцов несерпентинизированных ультрамафитов; при максимальном оптическом увеличении в минерале обнаружены цепочки включений двух типов - удлиненных (до 20 мкм в длину и до 2 мкм в ширину) и округлых, диаметром до 7 мкм (рис. 2).

\section{Оборудование и образцы}

Цепочки включений не выходят за пределы зерна минерала-хозяина, что позволяет предположить, что их морфология контролируется кристаллической структурой оливина. В образцах 7094, 5171, 757 удалось изучить состав ГЖВ методом рамановской спектроскопии (конфокальный рамановский спектрометр LabRAM HR800 Evolution с оптическим микроскопом Olympus BX-FM; объектив $100 \times(\mathrm{NA}=0.9)$; дифракционная решетка 600 штр/мм; SiCC-детектор; возбуждение линией 514 нм газового Ar-лазера; сигнал собирается в геометрии $180^{\circ}$; пространственное разрешение в объеме образца - до 5 мкм; диапазон значений рамановского сдвига - 800-4300 см ${ }^{-1}$; калибровка положения колебательных мод в спектре - по эмиссионным линиям 585.25 и 616.38 нм неоновой лампы Horiba (рис. 3 а) (Андреев и др., 2008)).

\section{Обсуждение результатов и выводы}

В исследованном диапазоне рамановского сдвига 800-4300 см-1 во всех изученных флюидных включениях проб оливина обнаружена лишь одна линия с максимумом 2909-2915 см-1 (рис. 3 б), связанная с метаном; линий, соответствующих газам $\mathrm{CO}_{2}, \mathrm{CO}, \mathrm{N}_{2}, \mathrm{H}_{2}, \mathrm{O}_{2}, \mathrm{NH}_{3}, \mathrm{H}_{2} \mathrm{~S}, \mathrm{SO}_{2}$, не обнаруже-

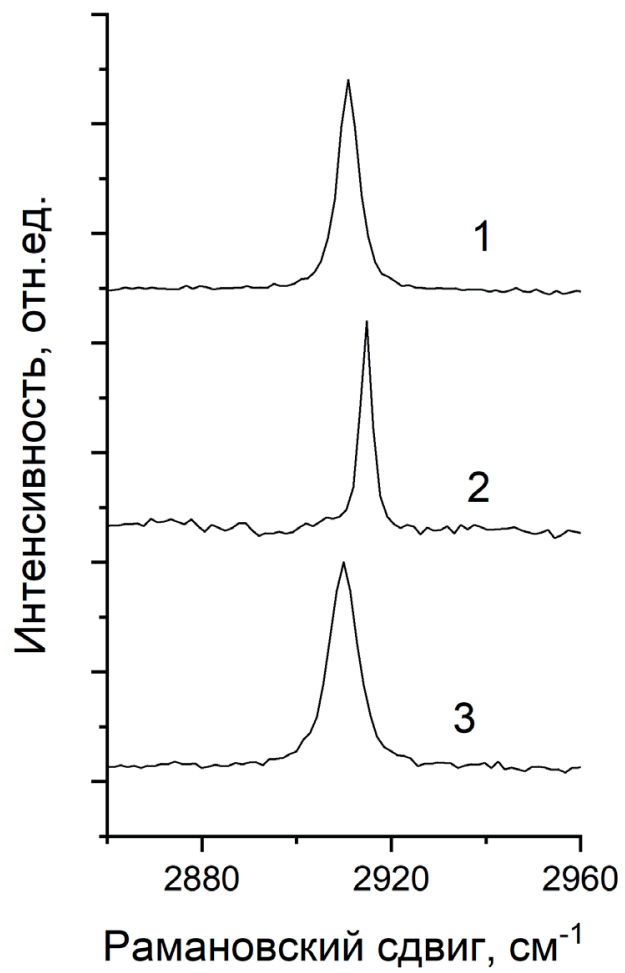

Рис. 3. Спектры рамановского рассеяния молекулы $\mathrm{CH}_{4}$ флюидных включений в пробах оливина: $1-7098 ; 2-5171 ; 3-757$.

Fig. 3. The Raman spectra of $\mathrm{CH}_{4}$ in fluid inclusion in olivine samples: 1- 7098; 2-5171; $3-757$. но, т.е. метан является единственным компонентом включений. По данным (Lu et al., 2007; Zhang et al., 2015) молекула $\mathrm{CH}_{4}$ имеет одну колебательную моду $\left(v_{1}\right)$ в области 2916-2918 см ${ }^{-1}$, соответствующую симметричному валентному колебанию связи С-Н. По данным исследования метансодержащих газовых смесей показано (Fabre et al., 1986), что с увеличением давления мода $v_{1}$ сдвигается от 2916-2918 до 2907-2910 см-1; последнее обусловлено деформацией электронного облака и как следствие изменением поляризуемости при сближении молекул $\mathrm{CH}_{4}$, что сопровождается искажением длины связи $\mathrm{C}-\mathrm{H}(\mathrm{Lu}$ et al., 2007). Представляется, что вариации максимума колебательной моды $v_{1}$ в пробах оливина связаны с вариациями давления во включениях.

Известно, что состав флюидов в системе С-О-Н контролируется величиной летучести кислорода $\mathrm{fO}_{2}$ (Sato et al., 1978; Рябчиков и др., 1983; Кадик и др., 1986; Wood et al., 1990), которая с глубиной закономерно уменьшается (Рябчиков 1999., McCammon et al., 2004). Зависимость состава С-О-Н-флюида от летучести кислорода позволяет приблизительно оценить место формирования ультрамафитов в разрезе мантии Земли. Согласно расчетов (Рябчиков 1999) чисто метановый состав флюида приурочен к границе верхняя мантия-переходная зона (на глубине 400 км) и соответствует величине летучести кислорода менее -12 $\log \mathrm{fO}_{2}$ ед. относительно буфера FMQ при давлении $>50$ кб (Кадик и др., 1986). При увеличении летучести кислорода 
мольная доля метана уменьшается, возрастает доля воды и водорода (Wood et al., 1990).

Исключительно метановый состав включений в несерпентинизированных ультрамафитах уральской складчатой области независимо от формационной принадлежности позволяет сделать вывод об их генерации в относительно близких условиях.

Работа выполнена в рамках государственного задания ИГГ УрО РАН (гос. регистрация № AАAА-A18-118052590026-5), анализ рамановского рассеяния выполнен при поддержке гранта РНФ № 16-17-10283.

\section{Литература}

1. Андреев А.И. Мухин С.В., Некрасов В.В., Никитенко В.А., Пауткина А.В. Модульная многофункциональная оптоволоконная спектрометрическая система [Электронный ресурc] // URL: http://www. avantes. ru/articles/up1. 2008.

2. Девирц А.Л., Гагауз ФГ., Гриненко В.А. и др. О происхождении водорода в ультраосновных породах Кемпирсайского массива // Геохимия. 1992. № 7. С. 1058-1064.

3. Кадик А.А., Луканин О.А. Дегазация верхней мантии при плавлении. М. Изд-во: Наука. 1986.

4. Лидин Г.Д., Матвиенко Н.Г., Зимаков Б.М., и др. Новые данные о выделениях водородных природных газов из ультраосновных пород // Доклады АН СССР. 1982. Т. 264. № 5. С. 1224-1228.

5. Рябчиков И.Д. Окислительно-восстановительные равновесия в верхней мантии // Докл. АН СССР. 1983. Т. 268. № 3. С. 703-706.

6. Рябчиков И.Д. Флюидный режим мантии Земли // Вестник ОГГГГН РАН. 1999. № 3(9). URL:http://www.scgis.ru/russian/cp1251/h_dgggms/3-99/riabchikov.htm\#begin.

7. Уханов А.В., Девирц А.Л., Иванов Н.Д. Изотопно-легкий водород на Кемпирсае (Южный Урал) // Доклады. АН СССР. 1987. Т. 293. № 3. С. 700-704.

8. Чащухин И.С., Вотяков С.Л., Щапова Ю.В. Кристаллохимия хромшпинели и окситермобарометрия ультрамафитов складчатых областей. Екатеринбург: Институт геологии и геохимии УрО РАН. 2007.

9. Fabre D., Couty R. Investigation on the density effects in the Raman spectrum of methane up to 3.000 bar - application to the determination of pressure in fluid inclusions trapped in minerals // Comptes rendus de l'Académie des Sciences, series II. 1986. V. 303 P. 1305-1308.

10. Lu W., Chou, I.M., Burruss, R.C., et al. Aunified equation for calculating methane vapor pressures in the CH4-H2O system with measured Raman shifts // Geochim. Cosmochim. Acta. 2007. V. 71 P. 3969-3978. DOI: https://doi.org/10.1016/j.gca.2007.06.004.

11. McCammon C., Kopylova M.G. A redox profile of the Slave mantle and oxygen fugacity control in the cratonic mantle // Contrib. Mineral. Petrol. 2004. V. 148/ Is.1. P. 55-68. DOI: https://doi.org/10.1007/s00410-004-0583-1.

12. Melcher F., Grum W., Simon G., et al. Petrogenesis of the ophiolitic Giant chromite deposits of Kempirsai, Kazakhstan: a Study of Solid and fluid inclusions in Chromite // Journal. Petrology. 1997. V. 38. № 10. P. 1419-1458. DOI: https://doi.org/10.1093/petroj/38.10.1419.

13. Sato M. Oxygen fugacity of basaltic magmas and the role of gas-forming elements // Geophys. Res. Lett. 1978. V. 5. № 6. P. 447-449. DOI: https://doi.org/10.1029/GL005i006p00447.

14. Wood B., Bryndzia L., Johnson K. Mantle oxidation state and its relationship to tectonic environment and fluid speciation // Science. 1990. V. 248. № 4953. P. 337-345. DOI: 10.1126/science.248.4953.337.

15. Zhang J., Qiao S., Lu W., et al. An equation for determining methane densities in fluid inclusions with Raman shifts // Journal of Geochemical Exploration. 2015. V. 171. P. 20-28. DOI: https://doi.org/10.1016/j.gexplo.2015.12.003. 